\title{
El libro antiguo: demanda, oferta y comercio en Internet
}

\author{
Manuel José Pedraza Gracia \\ Universidad de Zaragoza
}

\subsection{Resumen}

Se reflexiona sobre las sedes de Internet dedicadas al comercio del libro antiguo en Internet. Se examinan especialmente las dedicadas a la librería anticuaria, las casas de subasta y la bibliofilia. (Autor)

Palabras clave: Libro antiguo. Libro raro. Internet. Librería anticuaria. Casas de subasta. Tasación. Bibliofilia.

\subsection{Abstract}

Web sites devoted to the old book trading are discussed. Old book web sites produced by antiquarian booksellers, auction houses and book collectors are examined. (Author)

Keywords: Old books. Rare books. Rare materials. Internet. Antiquarian bookshops. Auction houses. Appraisal. Bibliophily. Book collectors.

\section{Introducción}

En el libro antiguo inciden diversas características destacables: es escaso, es bello, es difícil encontrarlo en perfecto estado, y, por consiguiente, suele ser también caro. Por todas estas causas, este mercado tiene algunas peculiaridades que lo aproximan más al mercado de la obra de arte o al de las antigüedades que al comercio del libro moderno, por ejemplo. En este mundo comercial entran en juego cinco factores: el vendedor-intermediario (librería o casa de subastas), el comprador (bibliófilo o institución), un medio que se utiliza para vender (venta directa o por medio de catálogo), un objeto que se vende (libro, aunque no siempre) y un precio por el que se compra.

La oferta profesional, más fiable, proviene esencialmente de las librerías anticuarias y casas de subastas. Este tipo de establecimientos, altamente profesionalizados, son los intermediarios entre el particular que se desprende de un libro antiguo y el particular o institución que lo adquiere. Los bibliófilos y las 
instituciones (sus bibliotecas) son quienes establecen la demanda de este mercado del libro antiguo. La bibliofilia como arte pretende la reunión de conjuntos armónicos de ejemplares relacionados por poseer una o más características comunes, bien sea desde la perspectiva del contenido del libro, bien sea desde la perspectiva formal $\mathrm{o}$, incluso, material. Las instituciones pretenden reunir el conjunto de obras que, de acuerdo con sus objetivos, se espera que posean o que en los momentos contemporáneos de la producción del libro hubieran poseído. El fin es, por tanto, en ambos casos, la propiedad del ejemplar, que, a su vez, mejora sus propias cualidades al formar parte del conjunto. En este tránsito del libro, estos establecimientos intermediarios ofrecen, además de las garantías derivadas del análisis profesional del objeto que ponen en el mercado, el valor añadido de sus productos: localización y focalización de la demanda, determinación de la importancia del ejemplar, limpieza, encuadernación y pequeña restauración si se precisa, descripción pormenorizada del mismo...

El libro es un objeto que por su propia naturaleza transmite el estado del conocimiento $-\mathrm{y}$, por tanto, al hombre, a la ciencia y a la sociedad que lo ha creado - atrapado en un momento concreto de su evolución (el de la concepción de la obra). Además, por él mismo, muestra también la situación del momento en el que fue creado (el de la fabricación del objeto). Todos estos aspectos determinan que resulte imposible apreciar el libro de una única manera. Esta versatilidad es la que especialmente incide en el comercio de ese objeto y en el interés que suscita, ya que sus múltiples facetas atraen compradores con intereses muy diversos. El libro como objeto de comercio tiene un precio y un valor en cuya estimación intervienen un número muy importante de variables. Algunas tienen que ver con la obra, otras con el ejemplar y otras son completamente ajenas al propio objeto. Las circunstancias que intervienen en el valor del libro generalmente inciden en su precio, pero es preciso hacer constar que valor y precio no siempre son magnitudes equiparables: Establecer el equilibrio entre ambos es propio de profesionales especializados.

\section{Librerías y casas de subasta (la oferta)}

La librería anticuaria es, sobre todo, un negocio que necesita ser gestionado, como tal. En él se gestionan, a su vez, documentos e información de alta especialización puesto que los documentos son muy complejos formal y estructuralmente. En él también se asesora y aconseja al cliente, que, en este caso, es, también, especializado. La información sobre los documentos y sus características debe ser gestionada y, especialmente, difundida. El librero anticuario aporta, de esta manera, un valor añadido al producto con el que comercia. Suelen prestar también un servicio de asesoría; y, además, en casi todas las librerías anticuarias se prestan servicios de búsqueda de documentos. 
Cualquier librería requiere, como punto de partida, un lugar y la adecuación de ese lugar para su función: ser comercio, en primer lugar, y ser librería, en segundo. Sin embargo, como primera diferencia esencial, el comercio del libro antiguo no precisa de un local abierto al público. Cierto número de librerías anticuarias solamente tienen domicilio fiscal. En ellas, las relaciones con proveedores y clientes se llevan a cabo esencialmente mediante el correo tradicional o el correo electrónico. Las librerías anticuarias, más que lugares, son conjuntos de personas que realizan dicha actividad. Su personal debe de tener la formación necesaria para poder desarrollar los fines de la librería. Se precisa:

a) Personal formado en la gestión en general, responsable de labores administrativas y financieras: adquisición, recepción, venta, control económico y financiero, entre otras.

b) Un conocimiento profundo sobre el libro antiguo que permita identificar las obras, proponer, si es preciso, medidas de conservación, adecuar con precisión el valor del libro al precio en el que se valora, confeccionar los catálogos y aconsejar y asesorar a los clientes.

c) La cantidad de información que se ha de manejar en la librería exige cada vez más un conocimiento de su gestión automatizada.

d) La relación con el cliente exige, además, cierto nivel de calidad humana, un cierto nivel de relaciones públicas.

Las labores de gestión se pueden dividir entre las funciones de carácter comercial y las de carácter administrativo. Las primeras engloban esencialmente las compras y las ventas: las segundas, por su parte, la gestión contable y la financiera. El flujo de mercancía novedosa que llega a cualquier negocio suele ser más o menos continuo, pero en la librería anticuaria esto no sucede de la misma manera. La librería anticuaria, normalmente, no tiene proveedores fijos que aporten novedades continuamente, el flujo de mercancía es discontinuo en la cantidad y en la calidad. Este aspecto es muy importante ya que afecta a todo el negocio. Es preciso mantener cierta disponibilidad financiera para abordar la compra de una gran biblioteca, por ejemplo, que puede servir para mantener una oferta importante durante cierto tiempo, a la par que se pueden producir momentos de bajo nivel de compras por ausencia de libros. Se produce en alguno de estos casos un curioso fenómeno que el librero Juan Francisco Pons expresa con claridad desde su experiencia (2001, p. 61): "lo usual en las relaciones comerciales es que 'el que vende pide y el que compra acepta, rechaza o propone una cifra alternativa'. En estas gestiones de compraventa, se da el caso de que el vendedor, es decir los dueños de la biblioteca, ignoran el valor comercial y proponen que sea el comprador el que pase su propuesta. Al mismo tiempo desconfían de su honradez y piden a otros libreros la misma operación, para quedarse con la mejor de las cifras". Se pro-

Scire. $9: 2$ (jul.-dic. 2003) 123-144. 
duce de esta manera una suerte de subasta. En cualquier caso, es perfectamente comprensible que el precio del libro que compra el librero no puede ser el mismo que el precio de su venta, ya que en ese caso la librería no cubriría sus gastos ni obtendría beneficio y, en consecuencia, fracasaría el negocio.

En el otro extremo de la línea se encuentra la venta, que es el resultado de una selección apropiada a la hora de haber adquirido los ejemplares. De hecho el librero anticuario muchas veces realiza compras para su librería teniendo ya presentes al bibliófilo o bibliófilos o a las instituciones que van a poder adquirir el libro en cuestión, por interés y por disponibilidad económica. La venta, por tanto, tampoco es exactamente igual que es las librerías modernas. El librero anticuario tiene una cartera de clientes de quienes conoce gustos y límites y con quienes mantiene un cierto nivel de relación y asesoramiento. Las ventas se realizan en ocasiones directamente al potencial comprador del ejemplar, sin pasar por darlo a conocer; labor técnica que, además, encarece el producto. Así el libro llega a personas que lo saben apreciar y posiblemente con un precio más económico. Esta práctica favorece al librero - que recupera la inversión de forma muy rápida - y al cliente - que obtiene un libro adecuado a su colección en condiciones preferentes. Este tipo de ventas favorece la relación entre el librero y el cliente: El librero fideliza al cliente y éste establece cierto nivel de confianza con el librero. Por esta causa, no puede ser considerado una descortesía hacia el resto de los clientes, sino como una práctica que permite capitalizar de forma rápida una inversión, como una política que asegura una cartera de clientes fijos y como un ahorro en las labores técnicas de descripción y comerciales de distribución. En ocasiones se procede a vender lotes enteros, que generalmente tienen la misma procedencia, ya que muchas veces el conjunto puede resultar mucho más atractivo para el comprador que las unidades por separado.

Como puede apreciarse, ni la compra ni la venta en la librería anticuaria son solamente actos comerciales. Ambos exigen un conocimiento técnico, del producto y del comprador. Este conocimiento incide en la valoración de los libros en uno y otro punto de la línea. Pero lo que interesa en este momento es que ninguno de estos actos precisa un local específico en el que realizar el acto de compraventa. La función administrativa dentro de la librería anticuaria se centra en los aspectos contables y financieros. Estos aspectos son los que permiten controlar la marcha del negocio. Una característica del negocio de la librería anticuaria es que la mayoría de los negocios se hacen al contado.

Existen además una serie de actuaciones de carácter técnico, centradas en el conocimiento del libro antiguo. Dentro de la actividad comercial que se centra en la compra y la venta es necesario partir de unos conocimientos muy profundos sobre el libro antiguo y sobre la demanda. Una vez adquirida la obra, es preciso identificarla de forma precisa, averiguar la edición en los repertorios que las

Scire. $9: 2$ (jul.-dic. 2003) 123-144. 
individualizan y establecer las características exclusivas del ejemplar. Cuando los ejemplares tienen con desperfectos se puede proceder a su restauración y a su encuadernación. Una vez realizadas todas estas actividades, el librero debe establecer un precio de venta para cada uno de los ejemplares estimando todos los aspectos posibles. Seguidamente se elabora el catálogo reflejando las características propias del ejemplar en una referencia que permita hacerse una idea lo más aproximada posible de la obra que se pone a la venta. Por fin, la relación que se produce con el cliente ha de ser potenciada, favoreciendo el asesoramiento y el consejo que el librero anticuario ofrece de forma desinteresada al cliente.

Los conocimientos sobre nuevas tecnologías en la librería anticuaria se fundamentan en la cantidad de información que se ha de manejar. Se ha de tener información pormenorizada de cuatro aspectos fundamentales y de uno algo más accesorio:

a) De los proveedores, poniendo en relación cada proveedor con los libros que se le han comprado.

b) Del objeto que se encuentra en venta, unidad por unidad, descendiendo en sus características hasta donde sea posible.

c) Del objeto que se ha vendido, independientemente del tiempo que haga que se haya producido la venta, unidad por unidad, relacionado con el cliente que lo adquirió.

d) De los clientes, incluyendo sus direcciones postales y las características de los libros que coleccionan.

e) En ocasiones, de libros que se solicitan al librero y de los que no se dispone o se dispuso en su momento, especificando las características que se exigían y el peticionario.

La red se ha convertido en un método eficaz para ofrecer libros y cada vez más se encuentran en Internet páginas web de librerías anticuarias que sirven para distribuir los libros. Las ofertas dispuestas en la red pueden llegar mucho más lejos que con la emisión de cualquier catálogo tradicional en papel. Especialmente útiles son los portales de venta que incorporan en una única base de datos los catálogos de muchas librerías anticuarias de diferente tamaño y especialización y de diversos lugares del mundo, llegando a ofrecer millones de libros en venta, aunque no siempre todos sean libros antiguos. Sus creadores son:

1) Librerías: Entre éstas se pueden localizar algunas que solamente venden a distancia y otras que poseen además un local abierto al público. Esencialmente se caracterizan por presentar de forma electrónica la librería, por ofrecer sus catálogos dispuestos de forma cronológicas y una dirección de correo electrónico para ponerse en contacto. 
2) Salones y ferias: Estas páginas se articulan generalmente como exposiciones de los libros especialmente valiosos ofrecidos por las diversas librerías participantes en la Feria de la que se trata.

3) Asociaciones de libreros: Su función principal es la de ofrecer reunidas las direcciones web y de correo de sus afiliados, noticias y boletines.

4) Portales de búsqueda de libros creadas por iniciativas diversas. Son páginas que prestan servicio de oferta conjunta y posibilidades de adquisición de un número importante de librerías anticuarias.

Entre las muchas páginas de librerías se mencionan a modo de ejemplo entre las extranjeras la de H. P. Kraus (http://hpkraus.com) de Nueva York y entre las españolas a Bardón en Madrid (http://www.libreriabardon.com/indmain.htm), París-Valencia (http://www.parisvalencia.com) en Valencia, Puvill (http:// www.puvill.com) y Llibreria Delstres (http://www.polybiblio.com/delstres) en Barcelona, y Hesperia (http://www.hesperialibros.com) en Zaragoza.

Las páginas creadas por ferias y salones son también frecuentes y se realizan especialmente para cada evento. Como ejemplo pueden mencionarse la del Salón del Libro Antiguo de Madrid organizado por el Gremio Madrileño de Comerciantes de Libros Usados (http://www.librerosmatritenses.com/feria.html) en España y el Marché de la Bibliophilie (http://foiresaintgermain.org/marchebibliophilie.html) en Saint Germain (Francia).

Un nuevo fenómeno surgido en el seno de la red son las ferias virtuales en las que los libreros exponen ejemplares de calidad. Estas suelen estar auspiciadas por las asociaciones profesionales. Un ejemplo es la Foire Virtuelle du Livre Ancien organizada por el Syndicat National de la Librairie Ancienne et Moderne (SLAM), en la que cada librero puede exponer hasta un máximo de 50 registros bibliográficos previo pago de una inscripción (http://slam.virtualbookfair.com).

Hay páginas web que reúnen la oferta comercial de diversas librerías anticuarias en una única base de datos. Si bien es cierto que estos instrumentos se han creado con un exclusivo fin comercial, también es cierto que representan un conjunto muy amplio de ejemplares tasados con los que poder establecer comparaciones. El principal de estos catálogos comerciales colectivos en español es Iberlibro (http://Iberlibro. com). Se presenta como un "catálogo colectivo de libros antiguos y modernos que abarca todo el ámbito del español y el portugués" y manifiestaba contener (en octubre de 2002) casi 900. 000 libros en venta de 165 librerías anticuarias y 40 editoriales. El mecanismo de funcionamiento de Iberlibro puede resultar paradigmático con respecto al del resto de los servicios similares de Internet. En esencia se parte de un formulario para realizar una búsqueda en la base de datos que contiene todos los ejemplares en venta. En este formulario puede limitarse la búsqueda exclusivamente a los libros antiguos en 
venta, y puede realizarse por autor, título, proveedor (librería) y descripción y restringirla por el precio. El resultado ofrece el número de ejemplares que responden a los criterios de búsqueda introducidos, restringidos por los valores precisados. En esta lista se proporcionan entre otros datos la librería que ofrece el libro y el precio que pide por él. Los precios pueden ser convertidos a la moneda que el

Fig. 1. Página de la Librería Bardón (Madrid).
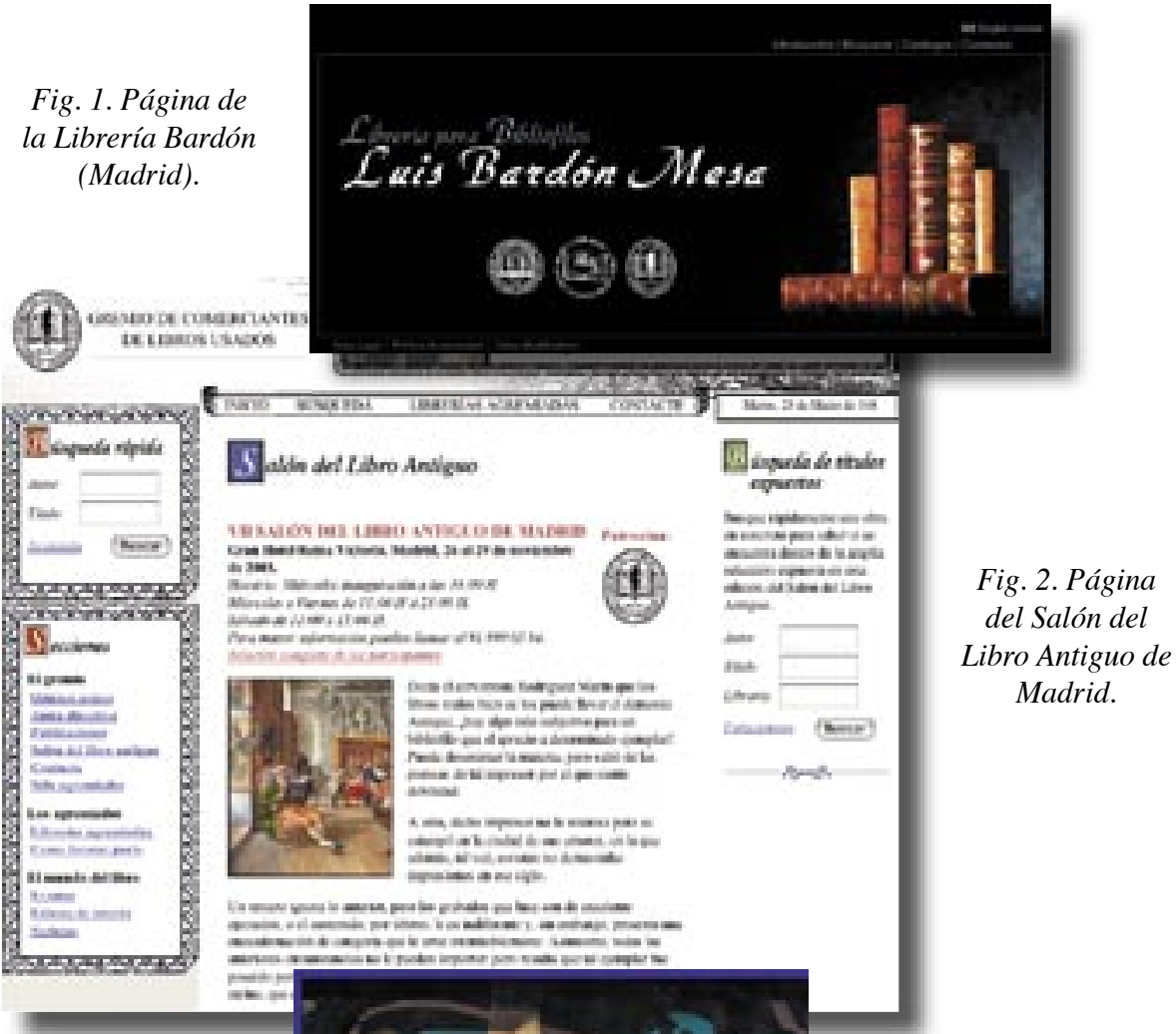

\section{virtual bookfair.com}

Fig. 3. Página de la Foire Virtuelle du Livre Ancien.

Scire. $9: 2$ (jul.-dic. 2003) 123-144. 
usuario desee con objeto de establecer las comparaciones necesarias independientemente de la moneda en la que la librería haya introducido el dato. La página web contiene además un directorio de librerías anticuarias que participan en la construcción de la base de datos. Otro servicio español de similar funcionamiento es el Portal del libro antiguo en castellano (http://www.libroantiguo.com), que ofrece un catálogo de libros raros, antiguos, curiosos, agotados. En este servio la búsqueda puede realizarse por título, autor y palabras o materias.

A partir del año 1999 han surgido numerosas sedes web semejantes, entre otras: Bibliophile.net (http://www.bibliophile.net), de carácter internacional; World

Fig. 4. Página de consulta en Iberlibro.com

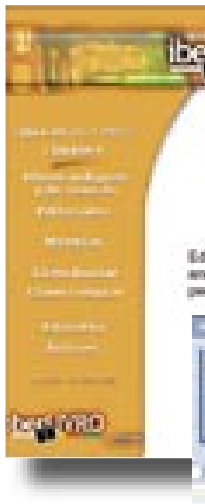

Fig. 5. Página del anuario Livre-Rare-Book.

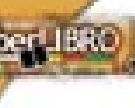

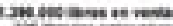

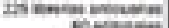
Theseatent

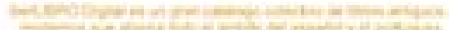

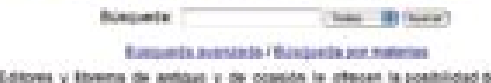

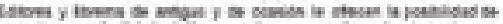

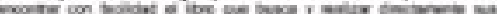

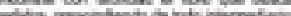
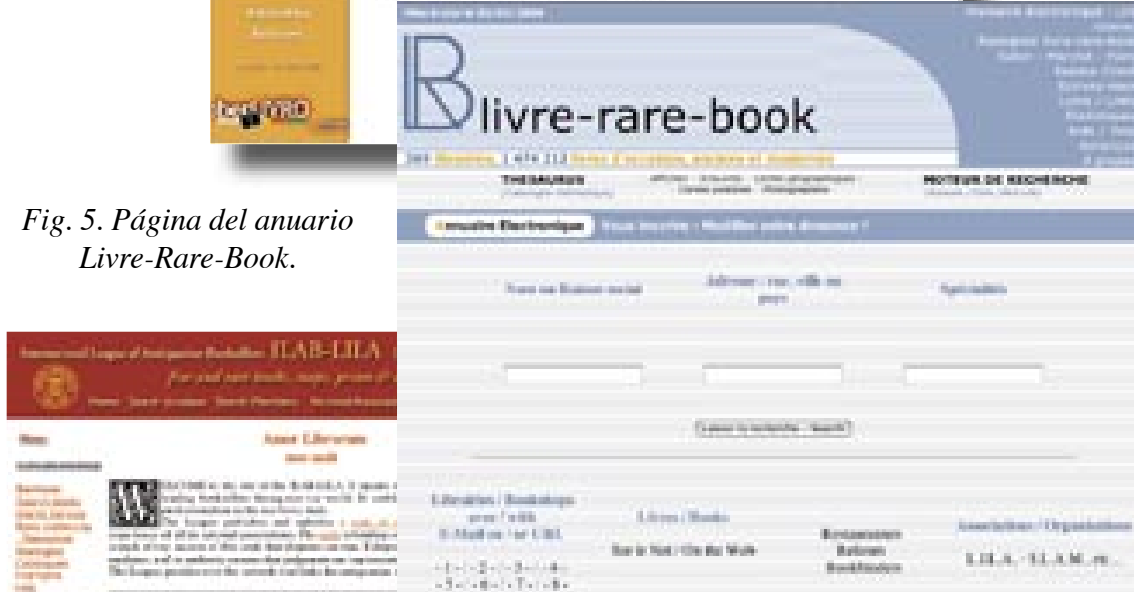

Briow

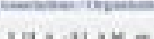

tovisuenera

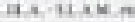

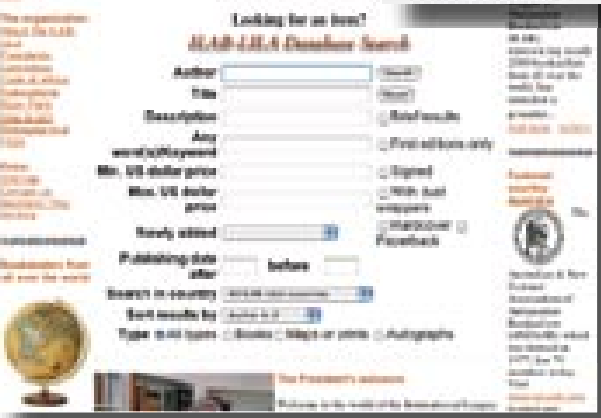

Fig. 6. Página principal de la ILAB-

LILA International

League of Antiquarian

Booksellers

Scire. $9: 2$ (jul.-dic. 2003) 123-144. 
Book Dealers, en los Estados Unidos (http://www.worldbookdealers.com/ welcome/welcome.asp); Maremagnum.com (http://www.maremagnnum.com), en Italia; Bibliorare.com (http://perso.wanadoo.fr/bibliorare), creada por la Association pour la Recherche des Livres Anciens, Rares et Précieux, en Francia; y AaZbooks (http://aazbooks.com), en Alemania. Uno de los más interesantes en el panorama internacional es el anuario Livre-rare-book contiene un buscador que ofrece cerca de 700.000 libros antiguos de 220 librerías anticuarias francesas. Además soporta una base de datos de casi 4.000 librerías anticuarias de todo el mundo con sus correspondientes enlaces y otra de ferias, con las mismas características, que se actualiza periódicamente (http://www.livre-rare-book.com/ anninter/annuaire.html). También merecen especial mención las promovidas por las asociaciones de libreros. Entre ellas destacan las de del Syndicat National de la Librairie Ancienne et Moderne (SLAM) (http://www.slam-livre.fr), en Francia; la Antiquarian Booksellers' Association of America (ABAA) (http://www.abaa.org); la de Libris (http://www.libris.es), en España; y la más local del Gremio Madrileño de Comerciantes de Libros Usados (http://www.librerosmatritenses.com). Además es de especial interés la de la ILAB-LILA International League of Antiquarian Booksellers (http://www.ilab-lila.com), de carácter internacional.

En niveles más modestos, pero más directos, el correo electrónico se está utilizando para remitir los catálogos de las librerías a los clientes preferentes y gestionar sus peticiones, como hace, por ejemplo, la Librería Mariano Romo (http://www.librosromo.com/). Los pagos se realizan desde la propia red utilizando tarjetas de crédito.

Estos métodos están consiguiendo abaratar los costes de administración de las librerías y, por consiguiente, mejorar las condiciones económicas de la oferta. No obstante, resultaría simplemente incomprensible que un bibliófilo o una institución adquiriese un libro de valor - un incunable, un gótico o un elzeviromediante estos métodos. Además, existe una legislación sobre el libro antiguo que rige en lo que respecta a la transmisión del libro antiguo y a la exportación del mismo. Las normas favorecen que los libros se queden dentro de los ámbitos regionales o nacionales en los que se encuentran, exigiendo una información precisa de los libros que se ponen en circulación. La utilización de los recursos electrónicos no supone contravenir la norma.

Las casas de subastas son otro sistema de comercio con diferencias remarcables. En primer lugar, casi todas ellas se dedican a la subasta de objetos diversos, no solamente o preferentemente libros; y, en segundo lugar, la casa de subastas no compra el libro que ha de subastar. El momento más complejo es el de tasar el libro y acordar el precio con el propietario. La casa de subastas percibe una doble comisión - tanto por parte del propietario como del comprador-; en total, un $30 \%$ del precio de remate. Son, por tanto, intermediarias y su relación con

Scire. 9 : 2 (jul.-dic. 2003) 123-144. 
el libro antiguo se centra en dos aspectos: la tasación y la elaboración del catálogo. El sistema de venta es el de puja, que puede ser presencial (en persona y por teléfono) y previo (estableciendo un límite máximo al que se está dispuesto a llegar). Una vez que se adjudica, el propietario abona el precio, y lo retira o se le envía a su domicilio. En todos los casos el Estado tiene reservado por ley el derecho de tanteo mediante la comparecencia de un representante del Ministerio en la subasta, quien hará constar su propósito una vez que termine el precio de remate del bien subastado. En las subastas en el extranjero, el Estado Español es un comprador más que actúa en las mismas condiciones que cualquier otro particular. Las casas de subastas utilizan la red de forma muy distinta a las librerías anticuarias. A estos establecimientos la red les permite reducir los costes de los catálogos, especialmente los de inclusión de imágenes. De esta manera se evita que los posibles compradores tengan que desplazarse hasta la casa de subasta para ver los ejemplares personalmente. El problema para el comprador es el mismo que en las librerías: los libros de alto precio tienen que ser revisados antes de su adquisición para evitar cualquier tipo de problemas.

Las casa de subastas incluyen en muchas ocasiones otros tipos de materiales bibliográficos - mapas, carteles, obra gráfica en general-, pero lo más frecuente es que sean solamente una parte de los que se subastan. De hecho, estos establecimientos se dedican sobre todo a la subasta de otros objetos que no son libros y que se rematan, normalmente, mucho más altos. Entre las casas de subastas más conocidas fuera de España no se puede omitir ni a Christie's (http: //christies.com) ni a Sotheby's (http://sothebys.ebay.com); y en España, también como ejemplo destacado por los que respecta al libro, hay que mencionar Durán (http://www.fernandoduran.com), la Casa de Subhastes de Barcelona (http: //www. subhastes.com) y Soler y Llach (http://www.philat.com/Soler-Llach/ home.html). El grupo Duran ha creado Duran Auctions On-Line con una página titulada eduran.com (http://www.eduran.com), que está especializada en subastas por medio de Internet, en la que se pueden encontrar libros relativamente recientes. La diferencia con el sistema tradicional radica en que toda la transacción se realiza exclusivamente por medio de la red.

\section{Coleccionismo, bibliofilia y reconstrucción patrimonial (la demanda)}

Normalmente, el comprador - la demanda - es un bibliófilo o una institución dedicada a la reconstrucción patrimonial. A parte quedan los compradores esporádicos movidos por la curiosidad.

Se ha definido al bibliófilo como persona que ama los libros y, por tanto, a la bibliofilia como el arte de quien ama los libros. Pero, por muchas definiciones que se analicen, no se suelen detener en el hecho de que el bibliófilo, además de estudiarlos y amarlos, adquiere y reúne esos libros, y que su posesión es consus-

Scire. $9: 2$ (jul.-dic. 2003) 123-144. 
tancial a la condición de bibliófilo. La bibliofilia no es una manía coleccionadora más ni posee rasgos homogéneos. De hecho cada bibliófilo desea una colección de libros distinta de la de cualquiera otro. Tampoco puede ser considerada como un método de inversión que permite, con el transcurso de un determinado lapso de tiempo, obtener unos beneficios con la venta de lo que se ha recopilado. El principio básico que rige este fenómeno desde el punto de vista del comercio del libro es que cada bibliófilo busca unos libros determinados y que cada libro (cualquier libro) tiene, con seguridad, un coleccionista potencial.

Cada bibliófilo actúa por motivaciones y gustos personales propios. Además de dedicarse coleccionar los libros, el bibliófilo es (o debiera ser) un investigador, perfecto conocedor de la materia o aspecto que vertebra su colección y su afición, que estudia y analiza sus ejemplares, obras punteras y principales para el estudio de la misma; o una persona orgullosa de pertenecer a un lugar o a una ciudad de la que aspira a conocer más y mejor recopilando todas las obras que hablan sobre ella, de las personas más importantes nacidas en ella, o publicadas en ella; un apasionado de la literatura que reúne las ediciones de determinadas obras y autores, primeras ediciones, variantes, etc. Pero, no basta con todo esto. Sobre todo, el bibliófilo debe poseer unos conocimientos de cierta relevancia sobre el libro y su historia, sobre Bibliografía, sobre la edición, las técnicas de impresión, la

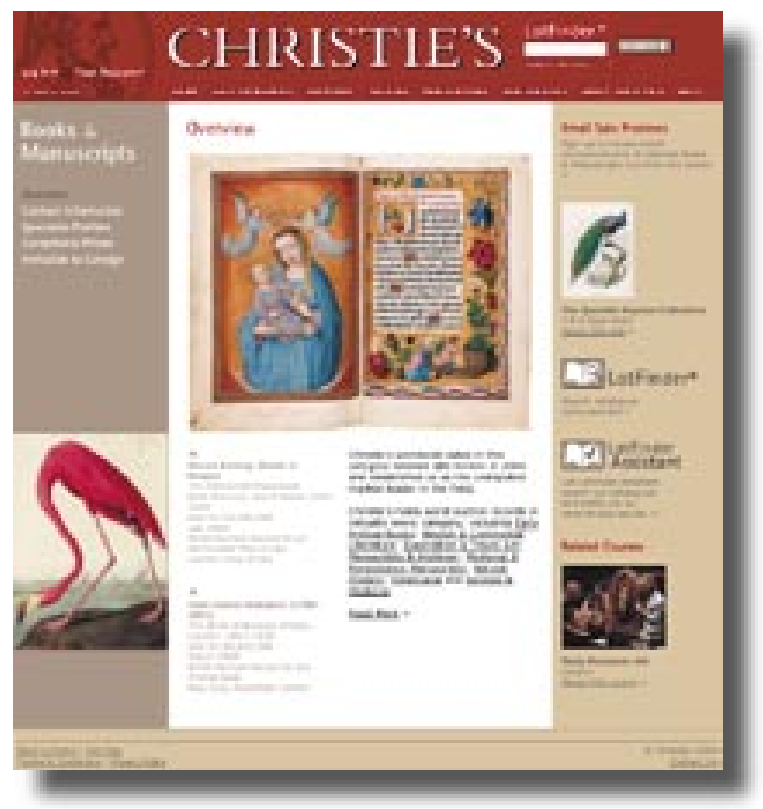

Fig. 7. Página dedicada a los libros en Christie’s.

Scire. $9: 2$ (jul.-dic. 2003) 123-144. 


\section{José Manuel Pedraza Gracia}

tipografía, los tipos y características del papel, la ilustración y la encuadernación. Son conocimientos que le permiten apreciar, valorar y discernir los ejemplares que constituyen su colección. A la par, debe tener unos conocimientos suficientes sobre preservación, conservación y patología del libro. En consecuencia, el bibliófilo tiene una doble formación, generalmente de carácter autodidacta en la temática o aspecto que estructura su colección de libros o impresos y, además, en el conocimiento del propio libro y de las técnicas y elementos para su fabricación. El bibliófilo estructura su colección en función de su propia visión del fenómeno que la articula. Por tanto, cada colección es forzosamente distinta de cualquier otra, como cada bibliófilo es distinto de otro y cada forma de ver una colección es diversa, independientemente de que el tema u objeto de la colección pueda ser el mismo. En esta circunstancia interviene también el propio documento, ya que los ejemplares de la misma edición y variante pueden no ser iguales, por contener firmas de autor, exlibris, etc. El bibliófilo ha preferido siempre la calidad y la busca más que la cantidad. Su biblioteca se caracteriza especialmente por su selección, y prefiere una biblioteca más bien pequeña pero muy seleccionada que una gran biblioteca de libros mediocres. De la misma manera, prefiere una biblioteca coherente, ya que un libro dentro de un conjunto homogéneo gana en interés. De hecho, el interés se transmite hacia el conjunto en lugar de hacia el elemento individual.

La inversión en libros se ha presentado, sobre todo en momentos recientes, como un negocio que puede aportar notables beneficios si se juega bien con las adquisiciones y las ventas. Esto, desde luego, nada tiene que ver con la bibliofilia sino con la especulación. En este caso el libro es para el inversor un objeto que se almacena hasta que se pueda obtener el beneficio deseado. Ni se estudia, ni se lee, ni se aprecia. No se puede confundir a este almacenista de libros caros con el coleccionista de libros preciosos y raros. El bibliófilo gusta de mirar sus libros y de conocerlos. Más que leerlos, lo que resultaría insuficiente para él, los estudia. El inversor no tiene ningún interés por el objeto, salvo en lo referente a su valor.

El bibliófilo requiere unas herramientas para llevar a cabo una afición que requiere conocimientos específicos. entre las que destacan los repertorios bibliográficos. Se han de incorporar, además, otras obras sobre la confección del libro, historias del libro, diccionarios de editores e impresores, ilustradores o calígrafos y repertorios de marcas de impresor o editor, entre otras. Por su parte, los catálogos de librero y de casas de subastas sirven como fuente de información en la que obtener referencias de nuevas obras para alimentar la colección; y también son los barómetros que establecen los precios de mercado de las distintas obras, bien sea por identidad con los ejemplares buscados o por similitud con ellos. Por fin, cumplen un papel importante las revistas especializadas o de bibliofilia.

Cada vez más, estas herramientas que requieren los bibliófilos están disponibles en Internet. En efecto, la red se ha ido convirtiendo en una gran feria en la 
que los bibliófilos buscan en el mundo entero nuevos libros para sus colecciones, en una gran obra de referencia para resolver dudas bibliográficas o bibliológicas, y en la fuente más fiable para establecer el estado del mercado del libro antiguo. De algunas de estas fuentes ya se habló en otro momento (Pedraza, 2002a) y del resto se trata más adelante.

Los bibliófilos se reúnen en asociaciones que crean sus propias páginas web y que permiten el intercambio de información y de ejemplares entre los socios. Esencialmente, se concentran en proporcionar información de calidad sobre lo que les es común - el libro- mediante diccionarios, historias del libro, del papel, etc., colecciones de textos e imágenes, bibliografías y un sin fin de útiles destinados a ayudar al coleccionista. A modo de ejemplo pueden citarse MFLibra, (http: //pages.infinit.net/mflibra1), Weblibris (http://weblibris.com), el ya mencionado Bibliorare.com (http://perso.wanadoo.fr/bibliorare), Textes rares (http://www. textesrares.com), Littera scripta (http://www.literascripta.com), Books \& book collecting (http://trussel.com/f_books.html) y Argus de bibliophile (http://www. argusdubibliophile.com), entre otros.

Muchos de los aspectos mencionados sobre los bibliófilos sirven también para las instituciones que compran libros antiguos. En bibliotecas se habla de procesos de selección y adquisición. Podría decirse que los procesos de selección y adquisición del libro antiguo en las bibliotecas, a tenor de los trabajos científicos publicados sobre el tema, se caracterizan por su inexistencia. En efecto, en muchas bibliotecas el fondo antiguo es algo que simplemente está. El material antiguo, por tanto, se suele considerar como la riqueza latente de la biblioteca, se preserva de cualquier peligro, se muestra a los visitantes importantes y se usa con el máximo cuidado posible; pero no es preciso enriquecerlo ni aumentarlo. La propia legislación vigente no

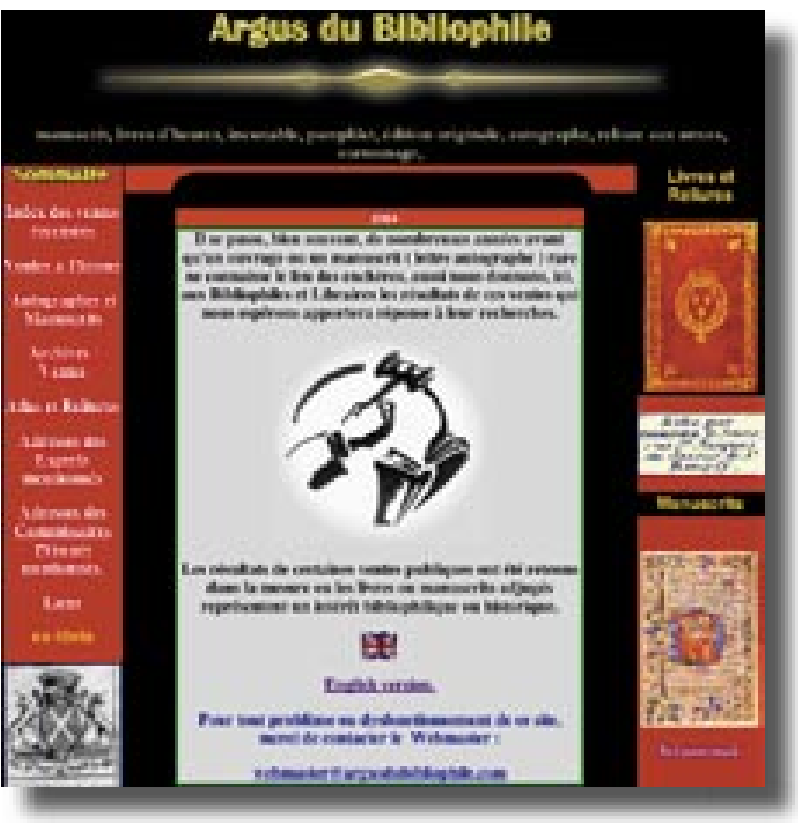

Fig. 8. Pagina principal de Argus de bibliophile.

Scire. $9: 2$ (jul.-dic. 2003) 123-144. 
entiende que sea objetivo prioritario el incremento del Patrimonio cuando dice en su preámbulo indica la Ley de Patrimonio Histórico Español: “[...] como objetivo último, la Ley no busca sino el acceso a los bienes que constituyen nuestro Patrimonio Histórico [...]”. La determinación de las bibliotecas que deben enriquecer su fondo antiguo o de las que han de dejarlo cerrado, suele encontrarse definida por la disponibilidad económica de los diversos centros. El concepto de selección se habría de trocar, cuando se habla de materiales antiguos, por el de reconstrucción patrimonial, que podría definirse como el conjunto de procedimientos de alta especialización técnica que conducen a la formación, mantenimiento y enriquecimiento de un fondo bibliográfico antiguo lo más representativo posible de los intereses de la biblioteca, bien sean científicos, literarios, artísticos... o bien sean locales, regionales, nacionales, etc. Se trata más bien de perseguir la recreación de una situación ideal conforme a las expectativas del usuario de la biblioteca en concreto o de la función que le ha sido asignada por la normativa. El concepto general de adquisición, dadas las especiales características que tiene este proceso, ha sido calificado en su denominación como adquisición retrospectiva (Carrión, 1987, p. 97). La influencia de Internet enel comprador es más bien escasa si se exceptúan la facilidad de acceso a catálogos individuales y colectivos de librerías y la posibilidad de ver, en remoto, fotografías de los lotes en las subastas.

\section{Los catálogos (el medio)}

Los catálogos son productos que emiten las librerías anticuarias y casas de subastas con objeto de informar a los clientes potenciales de los ejemplares que ponen en el mercado. Tienen un doble carácter técnico y comercial. Desde la perspectiva comercial son boletines de oferta en los que se muestran los productos disponibles con sus correspondientes precios. Suelen, por esta causa, incluir las condiciones de venta, de entrega del producto y de la forma de pago, las responsabilidades que contraen el comprador y el vendedor entre sí. Todas estas condiciones adquieren valor de compromiso para ambas partes, siempre que no contravengan lo establecido por la legislación. Desde la perspectiva técnica son boletines que contienen una descripción e identificación de los ejemplares que se incluyen especificando sus características esenciales. Sirven también para avalar bajo la responsabilidad del librero que la información técnica que se especifica sobre cada uno de los ejemplares reflejados es correcta. En caso contrario, la compraventa puede quedar anulada. Aunque no es siempre idéntica, su estructura es muy similar y perfectamente conocida por los clientes. Al principio, suelen contener las condiciones de venta o de subasta. Las referencias se ordenan por orden alfabético de sus entradas (nombre del autor, título), si bien, no se sigue para su elaboración ninguna norma específica como sucede en la catalogación en bibliotecas. Las referencias incluyen los datos identificativos de la obra:

Scire. $9: 2$ (jul.-dic. 2003) 123-144. 
a) Número de catálogo o de lote.

b) Descripción de la obra incluyendo la entrada, el título, la indicación de la edición, el pie de imprenta, la colación y el formato.

c) Presencia de ilustraciones - frontispicio, portada, viñetas, marca tipográfica o capitales...-, aspectos destacables de la composición - columnas, tipografía...-, encuadernación - tipo, decoración, momento en el que se realizó, superlibris... - , y otros aspectos relativos al ejemplar, como la presencia de exlibris o anotaciones manuscritas.

d) Estado de conservación, mencionando si el ejemplar tiene desperfectos.

e) Repertorios bibliográficos en los que figuran citas de forma abreviada de las ediciones a las que pertenece el ejemplar.

f) Comentario, estableciendo una valoración del autor, de la obra, del impresor o del ejemplar de cara a determinar su transcendencia desde la perspectiva científica, técnica, histórica, literaria o bibliofílica.

g) Precio de venta o de salida - de nuevo, un elemento comercial-; y, al menos en los catálogos de subasta de calidad, el precio estimado.

Finalmente, se incorporan unos índices temáticos. Tampoco responden estos índices a normas establecidas. Cada librería mantiene un listado de temas que no tiene por qué coincidir necesariamente con los de otra, ni en número ni en el término utilizado. De esta manera, se puede encontrar materias, aunque no se usen los mismos términos para mencionarlas, en unos catálogos se emplea "caballos" y en otros "caballería"; en unos "arte, arquitectura, urbanismo" reunidos y en otras separados; se pueden encontrar formas como "bibliografía", "autógrafos"...; y términos propios como "automobilia", "erótica", "judaica", "mariana", "vasconiana"... Los catálogos son en realidad el escaparate de las librerías anticuarias y de las casas de subasta. Pero, como puede apreciarse, tienen un componente técnico muy importante, por lo que algunos de ellos se han transformado en verdaderas obras de referencia para el estudio del libro antiguo. Sin embargo, algunos de estos catálogos no se distribuyen gratuitamente o tienen una difusión restringida.

La utilización de Internet por parte de los libreros para realizar sus ofertas no introduce variaciones importantes con respecto a los catálogos impresos en cuanto a los contenidos de los mismos. Sin embargo, el procedimiento de revisión del catálogo se ha modificado en la mayoría de los casos, con cierto disgusto por parte de los usuarios, desde la presentación para la lectura secuencial hacia los mecanismos de búsqueda clásicos de las bases de datos. Este fenómeno se produce especialmente cuando se trata de portales que se dedican a ofrecer de forma conjunta los catálogos de diversas librerías. Los usuarios (clientes) de las librerías gustan de leer el catálogo. Esta situación se ha modificado con los métodos de 
recuperación de información que se utilizan en la red. El catálogo es el escaparate del librero, por lo que encontraremos librerías que ofrecen libros verdaderamente antiguos, otras que mezclan estos libros con otros modernos y otras que en raras ocasiones ofrecen libros antiguos. Un nuevo producto que surge en la red de forma tímida - pero que se ha de desarrollar notablemente - son las páginas que de forma gratuita sirven de intermediarios entre la oferta particular y la demanda particular. Suelen ser creadas también por particulares. En la actualidad no ofrecen libros de valor. Como ejemplo puede citarse Livrissime.com, una página web creada por estudiantes (http://www.livrissime.com).

\section{Sucinta revisión del libro en el comercio anticuario (el objeto)}

Definir libro, en este mundo del comercio, es algo extremadamente complejo, ya que no solo todos los que se ofertan no son antiguos, sino que ni siquiera son libros. Si son libros, no tiene necesariamente que ser impresos, ni contener texto, si no lo son, no tienen necesariamente que estar impresos en papel, ni contener texto exclusivamente, ni imagen..., pero también hay libros, y algunos son antiguos. El libro es un objeto de una riqueza inmensa de matices que provienen del conglomerado de elementos de toda índole que lo constituyen. Estos factores internos tienen que ver con sus contenidos - que se puede identificar con la obra que el libro soporta - pero también con sus aspectos materiales - el libro como objeto-. Además, existen también una serie de características ajenas al propio libro que interesan específicamente a los bibliófilos. Entre los factores externos destacan la antigüedad, la rareza, el estado, la procedencia y determinadas particularidades del ejemplar como textos adjuntados, dedicatorias, manipulaciones, etc. Los factores internos que inciden en el libro pueden ser de dos tipos: los que tienen que ver con su materialidad como objeto y los que tienen que ver con la obra (el contenido del objeto). Entre los primeros destacan el origen material, el cuidado tipográfico, la ilustración, la encuadernación y la calidad del papel. Por último, el contenido es uno de los aspectos fundamentales para los bibliófilos, que se puede medir desde dos vertientes: la materia de la que versa el libro y la obra que el libro contiene (autor, título o colección). Bien es cierto que no todos estos factores influyen de la misma manera ni deben darse conjuntamente. Todos ellos, además, están sujetos a las modas. El bibliófilo gusta de poseer aquellos ejemplares más deseados por otros, lo que conduce a que crezca una determinada demanda sobre ejemplares o tipos de ejemplares muy concretos por cualquiera de los aspectos mencionados. Muchas de estas características no son excluyentes. Así, un ejemplar de la edición príncipe de una excelente obra literaria del siglo XVI, puede estar confeccionado con una excelente tipografía, poseer una buena encuadernación con un superlibris real, por ejemplo. Otros factores reducen su valor: una obra carente de interés, confeccionada con un papel de baja calidad, con una composición descuidada,

Scire. $9: 2$ (jul.-dic. 2003) 123-144. 


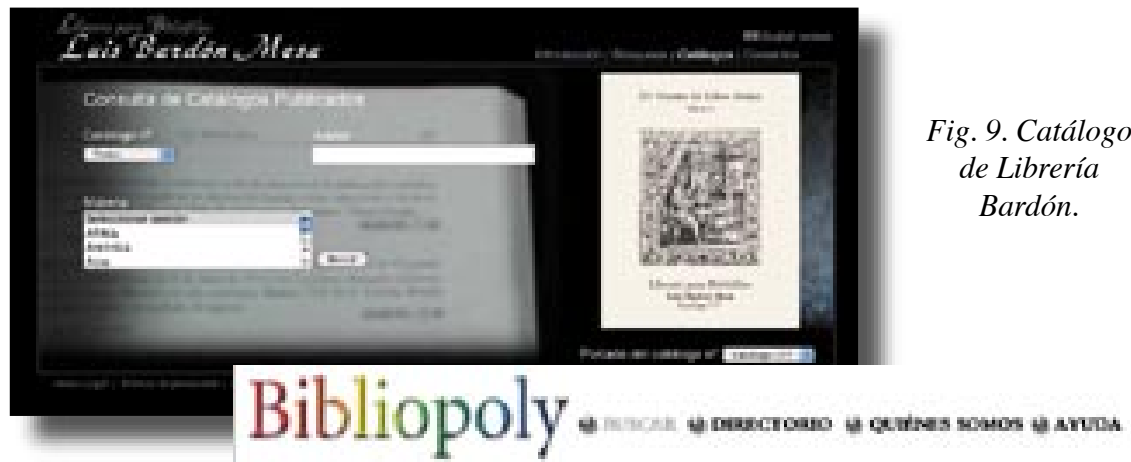

Fig. 10. Catálogo de la página web Bibliopoly, proyecto desarrollado por el librero anticuario Bernard Quaritch.

Formulario de bessqueda

\begin{tabular}{|c|c|}
\hline Antor & \\
\hline trues & \\
\hline Dates of irgaterta & \\
\hline Mo te tedchin: te & 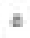 \\
\hline Howe & \\
\hline
\end{tabular}

Cuxeer pache

\section{Catcecria sn expernos}

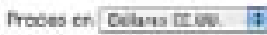
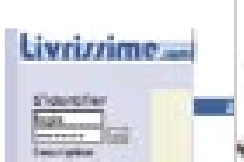

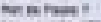

uvervati ift

moles (R)

bores int

vertike ISer

cantes iter

untere ical

Nomeris:

tanding

nines.

$\mathrm{r}^{x}$

texts

beil
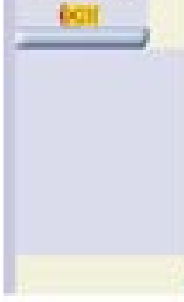

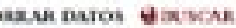

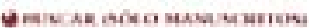

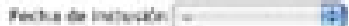

4)

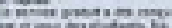

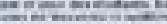

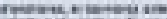

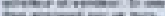
ase ancromes

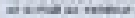

Besolmerimes 1

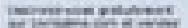

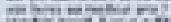

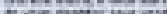

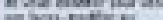

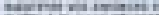

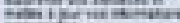
retenter the

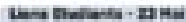
ises:

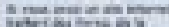
soremetir

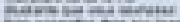

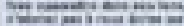

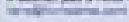

Catcgarias

Lo que selectane en ente menb aparecerit en ef campo "Catiegoria" dei famularia de be sogueda.

\section{Ruocon, niocoris Locica}

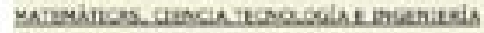
metorass

UTHEABSA miciosia

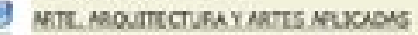

vüsro Tzema esenctiases

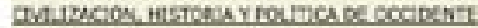

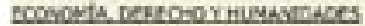

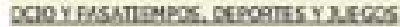

stueners

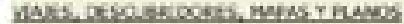

atses rergeties, gecoeark

cartoctas de couccontsqu esitaveroox Minceasia

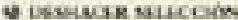

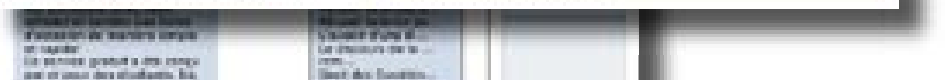
ain then:

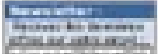

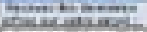

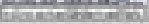

Fig. 11 .

Página

principal

de

livrissime.

com.

Scire. $9: 2$ (jul.-dic. 2003) 123-144. 
por muy antigua que sea la edición y se conozcan pocos ejemplares, por ejemplo, puede no despertar el más mínimo interés entre los bibliófilos.

No siempre el libro antiguo es libro de bibliófilo, aunque es raro el libro antiguo que no encaje en uno de los grupos mencionados. Tampoco todos los grupos tienen la misma influencia en el mercado, ya que están sujetos a distinta demanda. La demanda se articula generalmente desde dos vertientes contrapuestas: la tradición y la moda. La tradición ha definido grupos de obras y características de los ejemplares propios de la colección del bibliófilo, muchos de los cuales se han definido anteriormente. Algunas tienen como característica que son generales. Así, un plantino o un grolier resultan interesantes para muchas colecciones, e intemporales; y los libros góticos se coleccionarán siempre. No obstante, la mayoría se circunscriben a ámbitos lingüísticos o geográficos concretos. La moda también define otras colecciones, que se caracterizan por tener un ámbito más restringido en el espacio y en el tiempo. Sin embargo, algunas modas alcanzan con el tiempo - especialmente por el efecto de su originalidad o por la belleza de las producciones que recopilan - el nivel de la tradición.

La excelente relación existente entre el libro antiguo e Internet, que ya fue puesta de manifiesto en otro lugar (Pedraza, 2002b), ha dado como resultado páginas excelentes. Entre ellas se han de destacar las dedicadas a recopilar sedes web dedicadas en exclusiva al mundo del libro antiguo. Como ejemplo puede citarse Il libro antico, creAda en la Universidad de Udine por Angela Nuovo, Aldo Coletto y Graciano Ruffini (http://www.uniud.it/libroantico), que destaca por la estructuración muy estudiada de un gran número de enlaces interesantes.

\section{La valoración y tasación del libro (el precio)}

El valor de un libro está determinado por múltiples factores que van desde el ámbito de lo íntimo o afectivo - que hace que un determinado libro alcance para una persona un valor excepcional - hasta el del conocimiento universal, el estético, el histórico... Las circunstancias que intervienen en el valor del libro generalmente inciden en su precio, pero es preciso hacer constar que valor y precio no siempre son magnitudes equiparables. El precio es, en este nivel teórico, la traducción económica del valor. En un nivel más práctico ha sido definido como la cantidad económica máxima que alguien está dispuesto a pagar por el libro (Clavería, 2002, p. 173).

Uno de los factores condicionantes del precio es el propio proceso de compraventa y el fin que se persigue con la venta de los libros. Es fácil comprender que el precio de un libro que adquiere un librero no es el mismo que el precio al que lo vende. No es lo mismo tasar para la adquisición en bloque de un conjunto de libros o de ejemplares destinados a la rápida disposición de líquido que el ejercicio de búsqueda o espera del cliente adecuado para un libro específico. Por esta causa, se

Scire. $9: 2$ (jul.-dic. 2003) 123-144. 
puede decir que el mismo libro posee distintos precios según se pretenda vender al por menor, al por mayor u obtener líquido de forma rápida. Cuando se vende al por menor, el precio justo del libro sería el que un coleccionista paga en una librería. Pero hay que tener en cuenta que encontrar el coleccionista pertinente para un libro específico, puede no ser fácil y que las desviaciones juegan siempre en contra del vendedor. En la compra de libros por parte del librero el precio del libro es el que los vendedores al por menor están dispuestos a pagar por un libro y que lógicamente es menor que el precio que pagaría el coleccionista. Oscila notablemente con respecto al precio al por menor. Cuando se quiere obtener líquido el precio del libro resulta clave el tiempo que se esté dispuesto a esperar. Tampoco puede ser lo mismo tasar para un seguro - cuyo objeto es poder recuperar otro ejemplar en similares condiciones en caso de pérdida - que para la compra de una biblioteca. Una tasación para un seguro, para una donación o para una casa de empeños requiere valoraciones justificadas, avaladas y, especialmente, desinteresadas.

Otros factores que inciden sobre el precio se encuentran en el propio libro. El libro antiguo es un producto creado de forma artesanal. En el transcurso de su vida se ve sujeto a múltiples avatares que paulatinamente hacen que un ejemplar se vaya diferenciando de otro: la encuadernación, los signos de propiedad, las anotaciones, el guillotinado de los cortes, el ataque de insectos, el desgaste por el uso, la influencia del medio físico, el encartado de hojas en blanco, mutilaciones... Por esta causa, es prácticamente imposible encontrar dos ejemplares idénticos. Todos estos factores condicionan en una u otra medida y en una o en otra dirección el precio del ejemplar. Por esta causa, se puede hablar de la existencia de factores positivos y factores negativos. El precio de un ejemplar de una edición es un buen referente del precio de otro ejemplar de la misma edición, pero no es determinante. En primer lugar, la pertenencia a una edición no significa que sean idénticos, ya que pueden pertenecer a variantes distintas. Es preciso valorar, además, de forma objetiva el cúmulo de características que diferencian los ejemplares originalmente idénticos entre sí. De esta manera un ejemplar en perfecto estado es más caro siempre que un ejemplar con algún tipo de deficiencia; y cuanto mayor sea ésta más barato podrá adquirirse. De nuevo incide aquí el concepto de rareza: Los ejemplares en perfecto estado son más raros que los ejemplares con alguna deficiencia. También incide el concepto de demanda, los ejemplares perfectos son más buscados por los bibliófilos que los ejemplares con deficiencias por muy pequeñas que éstas sean, aunque en determinado momento, cuando el precio incide de forma determinante en el descenso de la demanda, tienden a equipararse. En muchas colecciones prevalece el criterio de calidad de los ejemplares por encima del criterio de cantidad, ya que actúa como principio general. Este cúmulo de avatares tiene mayor probabilidad de afectar al libro cuanto más antiguo sea. En consecuencia, un libro antiguo en perfectas condiciones resulta ser aún más

Scire. $9: 2$ (jul.-dic. 2003) 123-144. 
raro, más buscado por los coleccionistas y, sobre todo, más caro. Todavía más evidentes son estas apreciaciones cuando se trata de ejemplares únicos, manuscritos. A pesar de lo cual, condiciones como la de autógrafo o inédito intervienen en el precio de forma positiva frente a las de copia o publicado. Además de estos existen otros relacionados con el mercado como las modas, la competencia entre bibliófilos e instituciones y el componente mitológico.

En esta labor se pueden encontrar instrumentos de ayuda para la identificación y la determinación de precios. Los instrumentos que se poseen para identificar, averiguar la rareza y las características del libro antiguo (integridad, formato, edición, variantes...) son tan numerosos que difícilmente puede tener cabida en un trabajo como éste una referencia mínima a todos ellos. Solamente unos pocos indican los precios en los que en algún momento se han vendido, lo que no deja de ser un dato importante. Entre las herramientas fundamentales - especialmente valiosas y realizadas por profesionales - poder conocer el precio de los libros, de forma aproximada, destacan los ya mencionados catálogos de librería y de casa de subastas, especialmente cuando se puede llegar a conocer los remates. Otras fuentes tienen carácter histórico, pero pueden utilizarse, como el Brunet (1860-1880), el Graesse (1859-1869), el Salvá (1872) y el Heredia (1891-1894; Navarro Molina, 1913) o el Palau (1948-1977). Más moderna es El Mercado del Libro Antiguo Español. Una guía de precios (1999), que reúne unos 12.000 títulos con los precios con los que fueron ofrecidos en los catálogos de unas 30 librerías españolas, por lo que tiene un valor recopilatorio. Recientemente ha aparecido Anubi 2000. Anuario bibliográfico. Descripción y precios de libros antiguos del que se confeccionan dos versiones: una en papel y otra en CDROM. Incluye 65.000 referencias anuales de libros antiguos ofrecidas por cincuenta libreros y cinco casas de subastas, en cuyo

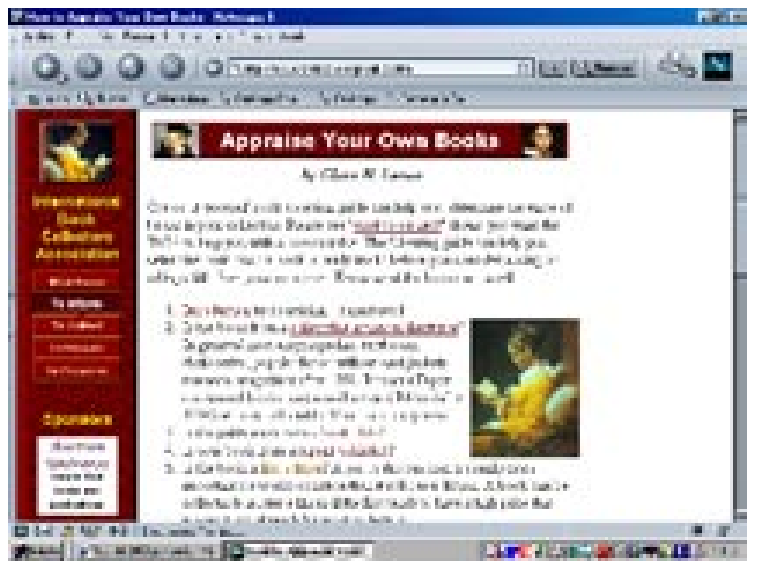

Fig. 12. Appraise your own books de Glenn H. Larsen. caso incluye los remates. Se actualiza periódicamente. Recientemente han aparecido también páginas de ayuda a la tasación. Se trata de páginas web destinadas a que el propio usuario pueda tasar sus propios libros. Para ello ofrecen una serie de herramientas, generalmente imperfectas, que, según indican las propias páginas web, están destinadas a usuarios inexperto. Entre dichas herramientas figuran indica-

Scire. $9: 2$ (jul.-dic. 2003) 123-144. 
ciones para identificar una primera edición, respuestas a preguntas más usuales y un servicio de consulta para aquellos casos que se resuelven mediante la ayuda prestada en la página web. Un ejemplo típico de este tipo de páginas es Your Old Books de Peter van Wingen (http://www.rbms.nd.edu/yob.html) o Appraise your own books, creado por Glenn H. Larsen para la International Book Collectors Association (http://www.rarebooks.org/values.html).

\section{A modo de conclusión}

El comercio del libro antiguo ha encontrado en Internet un espacio en el que desarrollar numerosos productos de ayuda a la demanda y a la oferta. La tendencia que se observa es que la imaginación de los profesionales del libro antiguo (libreros, tasadores, profesionales de la información) y coleccionistas (bibliófilos e instituciones) creará en los próximos años nuevos recursos que facilitarán el comercio reduciendo precios. En especial, están surgiendo numerosas páginas dedicadas a los libros antiguos que sirven de ayuda a la identificación, a la descripción y a la valoración. Especialmente, el instrumento principal de comercio, el catálogo, tiende a publicarse en Internet debido a la disminución de costes que esto supone. Por esta misma causa, las librerías y casas de subasta ofrecen utilidades y potencian el uso de la red para realizar las compras. No obstante, parece que se puede distinguir entre dos grupos de libros para la venta: los que pueden negociarse y transmitirse usando en exclusiva o preferentemente en la red, de coste bajo-medio; y los que no podrán comerciarse en la red, de coste medio-alto, aunque puedan verse favorecidos por los mecanismos electrónicos a la hora de ofrecer reproducciones, estudios y catálogos.

\section{Referencias}

Anuario bibliográfico 2000-2001 [Recurso electrónico]: Anubi: descripción y precios de libros antiguos. $2^{\mathrm{a}}$ ed. Valencia: Llibremanía, 2001.

Brunet, Jacques Charles (1880). Manuel du libraire et de l'amatuer de livres, 5e. ed. Paris: Firmin Didot, 1860-1880. 8 v.

Carrión Gútiez, M. (1987). Manual de bibliotecas. Madrid: Fundación Germán Sánchez Ruipérez, 1987.

Catalogue de la Bibliotheque de M. Ricardo Heredia, comte de Benahavis. Paris: Paul et Guillemin, 1891-1894.

Checa Cremades, J. L. (1999). El Libro Antiguo. Madrid: Acento, 1999.

Clavería Laguarda, C. (2002). Criterios objetivos y subjetivos de tasación: continental books y miseria. // Pedraza Gracia, M. J. (ed.). Tasación, valoración y comercio del libro antiguo (textos y materiales): Jaca, 2-6 de septiembre de 2002. Zaragoza: Prensas Universitarias de Zaragoza, 2002.

Devaux, Y. (1988). L'univers de la bibliophilie. Paris: Pygmalion, 1988. 


\section{José Manuel Pedraza Gracia}

Dexeus Mallol, M. (1993). De la valoración y tasación de libros. // El Museo de Pontevedra: Homenaje a Antonio Odriozola. 46 (1993) 335-350.

Dexeus Mallol, M. (2001). Las instituciones públicas ante la oferta de libros y documentos de interés histórico. // II Simposium Archivos familiares: valoración y tasación. Santander: Asociación para la Defensa del Patrimonio Bibliográfico y Documental de Cantabria, 2001.

Gallego, E.; Córdoba, I. (2002). Las subastas de libros: apuntes para no iniciados. // Pliegos de Bibliofilia, 17 (2002) 11-16.

Graesse, Jean George Théodore, Trésor de livres rares et prieux ou, Nouveau dictionnaire bibliographique contenant plus de cent mille articles de livres rares, curieux et recherchés d'ouvrages de luxe..., Dresden, Kuntze (etc.), 1859-1869. 7 v.

Le Menach, G. (1957). Initiation á la technique du livre et á la bibliophilie. Paris: Le Guide de Poche, 1957.

Marcos Pino, H. (1970). Gestión y administración de la librería. Madrid: Paraninfo, 1970.

Mendoza Díaz-Maroto, F. (2002). La pasión por los libros: un acercamiento a la Bibliofilia. Madrid: Espasa, 2002.

El Mercado del Libro Antiguo Español: Una guía de precios. Madrid: Ollero \& Ramos, $1999.2 \mathrm{v}$.

Navarro Molina, Gabriel (1913). Índice para facilitar el manejo y consulta de los catálogos de Salvá y Heredia. Madrid: Librería de los Bibliófilos Españoles, 1913.

Olaechea Labayen, Juan B. (1987). Nueva visión de la rareza de los libros. // Homenaje a Justo García Morales: Miscelánea de estudios con motivo de su jubilación. Madrid: ANABAD, 1987.

Palau y Dulcet, Antonio (1948-1977). Manual del librero hispanoamericano: bibliografía general española e hispanoamericana desde la invención de la imprenta hasta nuestros tiempos [...]. $2^{a}$ ed. corr. y aum. Barcelona, etc.: Librería Anticuaria de A. Palau, etc., 1948-1977. $28 \mathrm{v}$.

Pascual del Pino, C. (coord.) (1988). La librería: manual de gestión. Madrid: Confederación Española de Gremios y Asociaciones de Libreros, 1988.

Pedraza Gracia, M. J. (ed.) (2002a). Tasación, valoración y comercio del libro antiguo (textos y materiales): Jaca, 2-6 de septiembre de 2002. Zaragoza: Prensas Universitarias de Zaragoza, 2002.

Pedraza Gracia, M.J. (2002b). El libro antiguo en la red o El contacto de los extremos. // Scire. 8:2 (2002) 71-90.

Pol Arrojo, J. (1970). El libro y su comercialización. Madrid: Paraninfo, 1970.

Pons León, J. F. (2001). La óptica del librero especializado ante las tasaciones documentales. // II Simposium Archivos familiares: valoración y tasación. Santander: Asociación para la Defensa del Patrimonio Bibliográfico y Documental de Cantabria, 2001.

Puigvert Calderón de la Barca, A. (1970). Organización general de la librería. Madrid: Paraninfo, 1970.

Salvá y Mallén, Pedro (1872). Catálogo de la Biblioteca Salvá [...] enriquecido con la descripción de otras muchas obras, de sus ediciones, etc. Valencia: Imp. de Ferrer y Orga, 1872. 2 v. 